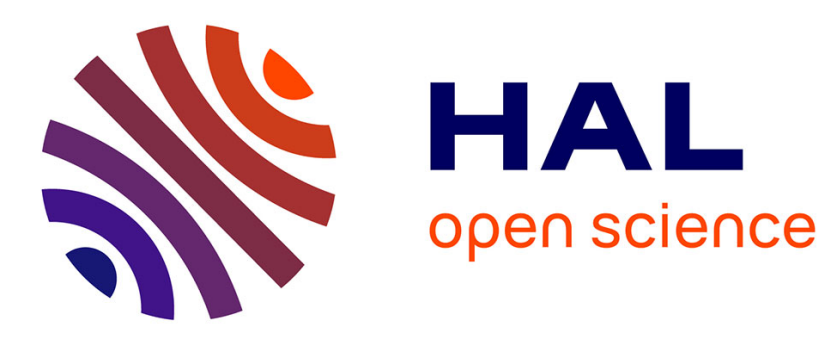

\title{
Signal amplification in a synchronized field emission NEMS
}

Thomas Barois, Sorin Perisanu, Philippe Poncharal, Pascal Vincent, Stephen T Purcell, Anthony Ayari

\section{- To cite this version:}

Thomas Barois, Sorin Perisanu, Philippe Poncharal, Pascal Vincent, Stephen T Purcell, et al.. Signal amplification in a synchronized field emission NEMS. 2012 International Conference on Electromagnetics in Advanced Applications (ICEAA), Sep 2012, Cape Town, South Africa. pp.551-553, 10.1109/ICEAA.2012.6328688 . hal-01565127

\section{HAL Id: hal-01565127 \\ https://hal.science/hal-01565127}

Submitted on 17 Dec 2018

HAL is a multi-disciplinary open access archive for the deposit and dissemination of scientific research documents, whether they are published or not. The documents may come from teaching and research institutions in France or abroad, or from public or private research centers.
L'archive ouverte pluridisciplinaire HAL, est destinée au dépôt et à la diffusion de documents scientifiques de niveau recherche, publiés ou non, émanant des établissements d'enseignement et de recherche français ou étrangers, des laboratoires publics ou privés. 


\title{
Signal amplification in a synchronized field emission NEMS
}

\author{
T. Barois ${ }^{1}$ S. Perisanu ${ }^{2}$ P. Poncharal ${ }^{3}$ P. Vincent ${ }^{4}$ S. T. Purcell ${ }^{5}$ A. Ayari ${ }^{6}$
}

\begin{abstract}
We present in this paper a study on highly resistive $\mathrm{SiC}$ nanowires in a singly clamped geometry. We demonstrate that these field emission nanoelectromechanical systems (NEMS) can be synchronized ton an external AC signal and act as an amplifier.
\end{abstract}

\section{INTRODUCTION}

A Nanoelectromechanical system (NEMS) is an electrical device capable of spatial motion at the nanoscale. Devices based on this principle are expected to perform ultrasensitive mass or force detection, for instance in biological applications, as well as to have potential for miniaturized, very lowpower consumption RF switches and time bases, for wireless applications. However, after more than ten years of development, their frequency stability is still the main obstacle for applications that aim to replace the quartz technology. Recently, it has been shown that several categories of NEMS can self-oscillate either by extrinsic feedback in a phase locked loop type configuration or with an intrinsic nanoscale active mechanism [1-4]. This opens the path for exploiting the ubiquitous cooperative phenomenon of self-oscillators: synchronization as observed in neurons, heart/breathing systems, population of flashing fireflies, lasers, charge density waves or Josephson junctions. Synchronization can be used for example for signal processing, filters, amplifiers, more sensitive sensors or clinical treatment of Parkinson disease. A major interest of synchronization for RF-NEMS applications is the possibility to stabilize their resonant frequency.

In the next paragraph we will present our experimental results on highly resistive self-

oscillating nanowires in a singly-clamped geometry. We will show that these devices show synchronization behavior under specific conditions; the third paragraph is dedicated to a basic analysis of the various mechanism involved in this phenomenon.

\section{RESULTS}

The samples studied in this experiment are $\mathrm{SiC}$ nanowires (see figure 1) with lengths of several tenth of microns and diameters around $100 \mathrm{~nm}$ attached to sharp tungsten tips (see table 1). The experimental set up consists of a UHV chamber with a scanning electron microscope column. The sample is placed on a XYZ piezoelectric nanomanipulator in front of a counter electrode.

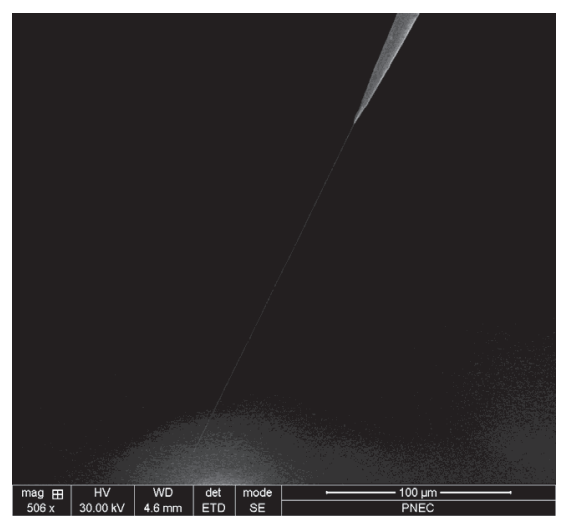

Figure 1: Scanning electron microscope image of sample 2 .

\subsection{Self-oscillation in field emission}

\footnotetext{
${ }^{1}$ Laboratoire de physicque de la matière condensée et nanostrucutres, Université Lyon1, CNRS, UMR 5586, F69622 Villeurbanne Cedex, France,

e-mail: thomas.barois"@"univ-1yon1.fr, tel.: +33 (0)4 724480 24, fax: +33 (0)4 72432648.

${ }^{2}$ Laboratoire de physicque de la matière condensée et nanostrucutres, Université Lyon1, CNRS, UMR 5586, F69622 Villeurbanne Cedex, France,

e-mail: sorin.perisanu"@"univ-1yon1.fr, tel.: +33 (0)4 724480 48, fax: +33 (0)4 72432648.

${ }^{3}$ Laboratoire de physicque de la matière condensée et nanostrucutres, Université Lyon1, CNRS, UMR 5586, F69622 Villeurbanne Cedex, France,

e-mail: philippe.poncharal"@"univ-lyon1.fr, tel.: +33 (0)4 724327 97, fax: +33 (0)4 72432648 .

${ }^{4}$ Laboratoire de physicque de la matière condensée et nanostrucutres, Université Lyon1, CNRS, UMR 5586, F69622 Villeurbanne Cedex, France,

e-mail: pascal.vincent"@"univ-1yon1.fr, tel.: +33 (0)4 724485 48, fax: +33 (0)4 72432648 .

${ }^{5}$ Laboratoire de physicque de la matière condensée et nanostrucutres, Université Lyon1, CNRS, UMR 5586, F69622 Villeurbanne Cedex, France,

e-mail: stephen.purcell”@"univ-1yon1.fr, tel.: +33 (0)4 724480 48, fax: +33 (0)4 72432648 .

${ }^{6}$ Laboratoire de physicque de la matière condensée et nanostrucutres, Université Lyon1, CNRS, UMR 5586, F69622 Villeurbanne Cedex, France,

e-mail: anthony.ayari”@"univ-1yon1.fr, tel.: +33 (0)4 724327 82, fax: +33 (0)4 72432648.
} 
A negative DC voltage of about $100 \mathrm{~V}$ is applied to the sample in order to be in the field emission regime, i.e. in the regime where electrons tunnel out of the nanowire toward the counter electrode. Above a field emission current of several hundreds of $\mathrm{pA}$ the nanowire position as well as its emitted current start to self-oscillate. The frequency of oscillation corresponds to the mechanical resonant frequency of the nanowire. This self-oscillation is due to an electromechanical instability of the system as described in details in [2-3]. It can be seen as a positive feedback loop between the position of the wire apex and its voltage and is similar to a vacuum tube oscillator where the role of the grid is played by the position.

\begin{tabular}{|c|c|c|}
\hline Parameter & Sample 1 & Sample 2 \\
\hline Length & $200 \mu \mathrm{m}$ & $200 \mu \mathrm{m}$ \\
\hline Radius & $110 \mathrm{~nm}$ & $160 \mathrm{~nm}$ \\
\hline Frequency & $45 \mathrm{kHz}$ & $32 \mathrm{kHz}$ \\
\hline Current & $3 \mathrm{nA}$ & $150 \mathrm{pA}$ \\
\hline
\end{tabular}

Table 1: Experimental parameters of the samples.

\subsection{Synchronization}

We have applied an additional moderate AC excitation (either by electrostatic or piezoelectric actuation) that locked the self-oscillation natural frequency of the nanowire to the external frequency as long as both frequencies do not deviate from each other by more than $10 \%$. Here we will concentrate on the electrostatic actuation.

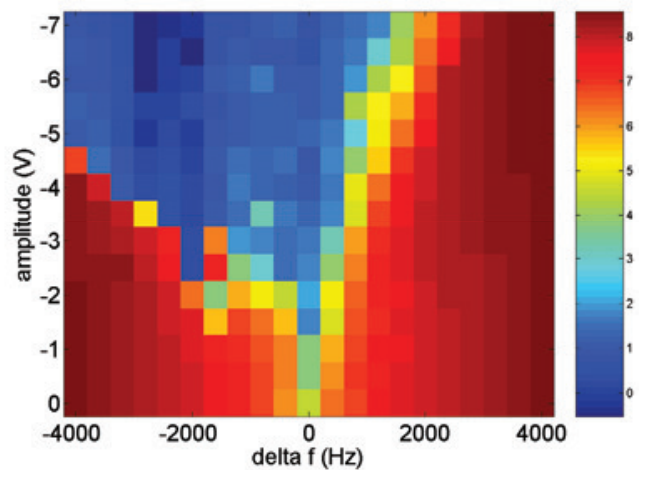

Figure 2: Dephasing diagram for various frequency mismatches (delta f) between self-oscillator frequency and external excitation and various excitation amplitudes in volt. The blue region corresponds to the locked or synchronized state and the red region to the unlocked state.

Figure 2 presents a typical synchronization diagram of a $\mathrm{SiC}$ sample showing the usual Arnold tongue shape. Such a diagram is obtained by recording the instantaneous field emission current with a secondary electron detector for various AC amplitudes and frequencies. Then, the phase of the self-oscillating signal is extracted by numerical analysis and compared to the external AC signal. As the system is rather noisy synchronization takes place only for an AC voltage above a threshold of the order of 1 Volt. Then, the higher the voltage, the higher the detuning range for synchronization. The amplitude of the synchronized AC signal is of the same order of magnitude as the DC current.

\section{ANALYSIS}

In a field emission NEMS, the current flowing through a nanowire splits into 4 different currents : a capacitive current, a motional current, a voltage modulated field emission current and a spatially modulated field emission current. This last current is often the dominant one and is at the origin of the electromechanical instability. Now, if an additional AC signal is applied, the capacitive current is a parasitic signal that can be reduced by carefully designing the capacitive environment and is not dominant in our case. The second current is a transduction current typical in NEMS actuated capacitively but is efficient only in the close vicinity of the resonant frequency (the frequency range is directly related to the quality factor of this forced oscillator). The third current, i.e. the voltage modulated current, is the one used in the old vacuum tube amplifier and is amplified by the synchronization phenomena that coupled it nonlinearly with the fourth current improving both amplification and bandwidth.

\section{CONCLUSION}

We presented in this paper the electromechanical behavior of $\mathrm{SiC}$ nanowires in a field emission configuration. We showed that in the self-oscillation regime, these devices can synchronized to an external AC signal in a wider range than a simple resonant circuit. This non-linear regime can be used as an electrical and force amplifier with potential application for ultrasound detection.

\section{Acknowledgments}

This work was supported by French National Agency (ANR) through Nanoscience and Nanotechnology Program (Projects NEXTNEMS nºNR-07-NANO008-01), through "Jeunes Chercheuses et Jeunes Chercheurs" Program (Project AUTONOME n ANR07-JCJC-0145-01) and CIBLE program of the région Rhône Alpes. The authors acknowledge the support of the "plateforme nanofils et nanotubes lyonnaise de l'Université Lyon 1". We thank the OMNTexperts for fruitful discussions. 


\section{References}

[1] A. Ayari, P. Vincent, S. Perisanu, et al., Nanoletters, 7, 2252 (2007).

[2] A. Lazarus, T. Barois, S. Perisanu, et al., Applied Physics Letters, 96, 93114 (2010).

[3] A. Lazarus, E. de Langre, P. Manneville, et al., International Journal of Mechanical Sciences, 52, 1396 (2010).

[4] P. G. Steeneken, K. Le Phan, M. J. Goossens, et al., Nature Physics, 7, 354 (2011). 